\title{
The Fish Family Poeciliidae as a Model to Study the Evolution and Diversification of Regenerative Capacity in Vertebrates
}

\author{
Diego Safian 1,2, Geert F. Wiegertjes ${ }^{1}$ and Bart J. A. Pollux ${ }^{2 *}$ \\ ${ }^{1}$ Aquaculture and Fisheries Group, Department of Animal Sciences, Wageningen University, Wageningen, Netherlands, \\ ${ }^{2}$ Experimental Zoology Group, Department of Animal Sciences, Wageningen University, Wageningen, Netherlands
}

\section{OPEN ACCESS}

Edited by:

Wayne Iwan Lee Davies,

Umeå University, Sweden

Reviewed by:

Jennifer Rodger,

University of Western Australia,

Australia

David Bierbach,

Leibniz-Institute of Freshwater Ecology and Inland Fisheries (IGB),

Germany

${ }^{*}$ Correspondence:

Bart J. A. Pollux

bart.pollux@wur.nl

Specialty section:

This article was submitted to Behavioral and Evolutionary Ecology,

a section of the journal

Frontiers in Ecology and Evolution

Received: 01 October 2020 Accepted: 01 March 2021

Published: 25 March 2021

Citation:

Safian D, Wiegertjes GF and Pollux BJA (2021) The Fish Family Poeciliidae as a Model to Study the Evolution and Diversification of Regenerative Capacity in Vertebrates.

Front. Ecol. Evol. 9:613157. doi: 10.3389/fevo.2021.613157
The capacity of regenerating a new structure after losing an old one is a major challenge in the animal kingdom. Fish have emerged as an interesting model to study regeneration due to their high and diverse regenerative capacity. To date, most efforts have focused on revealing the mechanisms underlying fin regeneration, but information on why and how this capacity evolves remains incomplete. Here, we propose the livebearing fish family Poeciliidae as a promising new model system to study the evolution of fin regeneration. First, we review the current state of knowledge on the evolution of regeneration in the animal kingdom, with a special emphasis on fish fins. Second, we summarize recent advances in our understanding of the mechanisms behind fin regeneration in fish. Third, we discuss potential evolutionary pressures that may modulate the regenerative capacity of fish fins and propose three new theories for how natural and sexual selection can lead to the evolution of fin regeneration: (1) signaling-driven fin regeneration, (2) predation-driven fin regeneration, and (3) matrotrophy-suppressed fin regeneration. Finally, we argue that fish from the family Poeciliidae are an excellent model system to test these theories, because they comprise of a large variety of species in a well-defined phylogenetic framework that inhabit very different environments and display remarkable variation in reproductive traits, allowing for comparative studies of fin regeneration among closely related species, among populations within species or among individuals within populations. This new model system has the potential to shed new light on the underlying genetic and molecular mechanisms driving the evolution and diversification of regeneration in vertebrates.

Keywords: Poeciliidae, evolution, fin, regeneration, diversification

\section{INTRODUCTION}

Regeneration is one of the most intriguing phenomena in nature. In the last decades, the capacity of regenerating a damaged or lost structure has been a central interest for scientists. Understanding this process may potentially lead to new treatments of medical problems involving tissue damage, such as injuries, cancer, aging and disease (Mao and Mooney, 2015), but also represents an interesting case of study for developmental and evolutionary research. Regeneration is a complex process that involves the regulation of different cell types and reports have shown that it can recapitulate cellular and 
molecular processes that take place during early development (Martin and Parkhurst, 2004; Ghosh et al., 2008). Remarkably, this capacity is widespread in different phyla, yet regenerative ability has diverged, being absent or restricted to specific tissues or short time-windows after birth in many animal lineages (Porrello et al., 2011).

Regeneration can be classified into three types: (1) Physiological regeneration, which is tissue regeneration that takes place under normal conditions, i.e., not in response to injury. This is a continuous process that supports the turnover of particular cells in a structure throughout the life of a given organism, maintaining the tissue homeostasis (e.g., the continuous replacement of cells in the epidermis and blood). (2) Reparative regeneration, which refers to an organism's capacity to repair organs or tissues after a minor injury (e.g., healing of blood vessels and skin cells after a cut). (3) Restorative regeneration (or "true regeneration"), which consists of the capacity to regrow a fully functional, scar-free structure after loss of that structure (e.g., regeneration of limbs, tail, external gills and fins). Several remarkable examples of restorative regeneration can be found in nature from invertebrates to vertebrates. Flatworms (Planaria sp.; Ivankovic et al., 2019) and polyps (Hydra sp.; Vogg et al., 2019) are highly regenerative invertebrates that can regenerate most of their structures after severe injuries. Some species can even form an entirely new individual from a small body fragment. This capacity is also present in vertebrates, but here the regenerative capability is often reduced in extent or restricted to specific structures (Galliot et al., 2017). For instance, many lizards can regenerate a missing tail but fail in regenerating other structures such as limbs (Alibardi and Toni, 2005). This review will only address restorative regeneration to which, for the sake of simplicity, we will hereafter refer to as "regeneration."

\section{EVOLUTIONARY ORIGINS OF REGENERATION: A LONG-STANDING OPEN QUESTION}

One of the more intriguing questions regarding regeneration is how this trait has evolved in different lineages. It is clear that regeneration ability is widely distributed in several phyla, but the origin of this capability remains to be determined. Based on the general similarity in the regenerative program such as induction of wound epidermis and involvement of similar cell signals controlling the process (e.g., Wnt, Fgf, and Bmps) in distant taxa, it has been hypothesized that regeneration perhaps arose in early animals as an epiphenomenon of development and was subsequently lost several times in different lineages (Bely and Nyberg, 2010; Galis et al., 2018). However, the cellular mechanisms that underlie the regeneration program can be remarkably diverse, suggesting that perhaps regeneration is not an ancestral trait but that instead it represents a novel innovation that has evolved independently many times in different phyla as an adaptive trait (Tiozzo and Copley, 2015).

Although it is not clear yet how regeneration evolves, three potential causes have been proposed to explain a lack of, or reduced, regenerative ability in animals (Bely, 2010): (1) The first is that the regenerative capacity becomes restricted as the individual keeps developing, due to a reduction of cellular plasticity. This is especially relevant for those regenerative processes that require dedifferentiation or transdifferentiation of local, post-mitotic cells, which again must enter into a new cell cycle to lose their identity, divide and differentiate. Galis et al. (2003) proposed that regeneration is only possible for structures that during embryogenesis develop independently of transient organs. They argued, for example, that limb regeneration in amniotes is not possible because embryonic limb development requires the support of interacting signals from the somites, which are no longer present during adulthood. (2) Another possibility is that other vital processes such as growth and reproduction become favored over regeneration, increasing the threshold for investment into regeneration. In these cases, regeneration could simply be too costly to occur (Box 1), especially if the missing tissue is dispensable for survival. In these animals, regeneration is a maladaptive trait that is selected against. (3) Finally, environmental conditions such as temperature and food availability may modulate the ability to regenerate a damaged tissue. Intriguingly, a recent study by Hirose et al. (2019) suggests that the ability to regenerate heart tissue might be modified during the evolutionary transition from exothermy to endothermy. This study showed that heart regeneration competence is associated with low number of polyploid cardiomyocyte in 41 vertebrate species (Hirose et al., 2019). In addition, it also revealed that thyroid hormone signaling (which is involved in regulating corporal temperature and is produced in higher levels in endotherms) increased cardiomyocyte polyploidization and inhibited heart regeneration in newborn mice. Remarkably, thyroid hormones conserved their inhibitory capacity in adult zebrafish, a species with high heart regenerative capacity but naturally low levels of thyroid hormones (Hirose et al., 2019). This study provides the first empirical evidence in support of the idea that habitat adaptation can shape the evolutionary trajectory of the regenerative capacity.

It is clear that internal and external cues converge to modulate an organism's regenerative ability and that these can be as diverse as the animal kingdom. Among regenerative species, fish have become an interesting system to study regeneration due to their restorative potential. Fins, in particular, are increasingly recognized as a relevant model to understand the factors shaping regenerative capacity, because next to their primary function (i.e., swimming) (i), fins are often fundamental for secondary functions that directly impact fitness (e.g., swimming, feeding, reproduction) and (ii) are (contrary to other regenerative tissues, such as the heart and spinal cord) often directly exposed to biotic and abiotic factors.

\section{FISH FINS AS A MODEL SYSTEM TO STUDY REGENERATION}

Traditionally, a limited number of model species have been used to study regeneration. Yet, in the recent years, important efforts have been made to expand the diversity of animals used in regeneration research, including species from distantly 
BOX 1 | Immune system and fin regeneration.

After an injury, non-regenerative species respond by forming a scar that rapidly closes the wounded area without regenerating the lost structure. Regenerative organisms, on the other hand, are able to form a wound epidermis that is compatible with regeneration. It has been argued that (the absence of) an immune response is crucial to determine the type of repair response. Therefore, the evolution of a more efficient immune system (immune competence) has been linked to the loss of regeneration in several advanced taxonomic groups (Alibardi, 2017; Julier et al., 2017).

Injuries almost always induce a response from the immune system. First, cells of the innate immune system such as neutrophils and macrophages provide a rapid defense against potential pathogens invading the damaged tissue. Neutrophils are the first immune cell to respond to the open wound; however, these granulocytes appear to be dispensable for fin regeneration (Li et al., 2012). In contrast, macrophages play a predominant role in the restoration of tissue homeostasis and the timely presence of macrophage subtypes seem to be relevant during different stages of appendage regeneration (Godwin et al., 2013; Petrie et al., 2014; Paredes et al., 2019). In zebrafish, Nguyen-Chi et al. (2017) reported that the two most apparent subtypes of macrophages, pro-inflammatory (M1) and anti-inflammatory (M2), actively participate during fin regeneration and that caudal fin amputation in larval zebrafish induced an early inflammatory response characterized by an accumulation of both subtypes of macrophages. This accumulation would eventually result in an increase of macrophage-derived tumor necrosis factor alpha (Tnfa), which in turn further promotes the recruitment of more macrophages and participates in the initiation of blastema cell proliferation (Nguyen-Chi et al., 2017). Upon this early signal, M2 macrophages remained high in number while the M1 macrophage population decreased in the wound area, suggesting that M2 macrophages are likely involved in the remodeling of cells during fin regeneration (Nguyen-Chi et al., 2017). This idea is further supported by recent studies on adult zebrafish showing that macrophages are capable of attenuating inflammation after injuries (Hasegawa et al., 2017) and that macrophage accumulation within the regenerating tissue is needed for proper fin regeneration, in line with a pro-regenerative gene profile (i.e., expression of genes associated with blood vessel development, leukocyte migration, and regulation of the inflammatory response) (Sanz-Morejón et al., 2019). In addition, it has been proposed that a population of tissue-resident macrophages contributes in regenerating fin after injury (Morales and Allende, 2019). Interestingly, the responses of macrophages and neutrophils in zebrafish seem to be dependent on the type of fin injuries i.e., while thermally induced wounds were resolved by regeneration, infected wounds lead to persistent inflammation and minimal tissue repair, suggesting that a more robust immune response (as induced by bacterial infection) restricted the extent of regeneration (Miskolci et al., 2019).

The adaptative immune system also participates in the regenerative process, but this response is typically slower and probably associated with maintaining tissue homeostasis during the regenerative process. A specialized group of $T$ cells, the regulatory $T$ cells $\left(T_{\text {reg }}\right)$, are particularly relevant to tissue regeneration, at least in mammals: $T_{\text {reg }}$ stimulate self-tolerance, prevent autoimmune and autoinflammatory disorders, and contain excessive inflammatory responses to infection and tissue damage by modulating the activity of effector cells of the immune system (Josefowicz et al., 2012). Additionally, tissue-specific Treg with proficiency in controlling tissue homeostasis and repair have been identified in mammals (Sharma and Rudra, 2018). In fish, Treg have also been identified with apparent conservation of many of the functions reported for higher vertebrates (Sugimoto et al., 2017). Zebrafish Treg rapidly migrate and infiltrate the damaged organs, while conditional ablation of this cell type in adult zebrafish blocked tissue regeneration by impairing proliferation of blastemal cells (Hui et al., 2017; Zwi et al., 2019). Different to its role in tissue/wound healing, other components of the adaptive immune system have not been directly linked to fin regeneration capacity, yet should not be disregarded as, in other vertebrates, several of these components are present in the blastema during limb regeneration (Leigh et al., 2018).

phyla such as Platyhelminthes (e.g., Schmidtea mediterranea; Ivankovic et al., 2019), Cnidaria (e.g., Hydra vulgaris; Vogg et al., 2019), Arthropoda (e.g., Drosophila melanogaster; Fox et al., 2020), Echinodermata (e.g., Patiria miniata; Cary et al., 2019) and Chordata, which include species from different class such as Actinopterygii (e.g., zebrafish; Marques et al., 2019), Amphibia (e.g., Xenopus leavis and Ambystoma mexicanum; Joven et al., 2019; Phipps et al., 2020), Reptilia (e.g., Podarcis muralis; Alibardi, 2017) and Mammalia (e.g., Acomys cahirinus; class Mammalia; Maden and Varholick, 2020).

Comparative studies on more closely related animals that have diverse regenerative capacities in a well-defined phylogenetic framework are likely to shed further light on the evolution of this trait and the selective pressures that favor it. In this context, fishes represent an excellent system to study the evolution of regeneration. Fishes are an extraordinary diverse group of animals (Hughes et al., 2018) and several studies have reported on the presence of regenerative properties of several different tissues, such as the heart, spinal cord, brain, liver, and fins (Gemberling et al., 2013). For example, all bony fishes (Superclass Osteichthyes) that have been studied so far have shown at least some degree of fin regeneration. However, while homomorphic (complete) fin regeneration has been reported in lobe-finned fishes (class Sarcopterygii) and the early ray-finned fish lineages (class Actinopterygii; e.g., Polypteriformes, Lepisosteiformes, Cypriniformes, Esociformes, and Salmoniformes; Figure 1, blue branches), heteromorphic or incomplete fin regeneration (i.e., resulting in an unfinished, abnormal fin shape) has additionally been found in the more recent lineages (Neotelesots, i.e., Cichliformes, Cyprinodontiformes, Perciformes, and Scorpaeniformes; Figure 1, red branches) (Wagner and Misof, 1992; Cuervo et al., 2012; Darnet et al., 2019), suggesting that the regenerative capacity has been reduced in these latter groups. Yet, a broader study addressing the causes and underlying molecular mechanism of homo- and heteromorphic fin regeneration is currently missing.

\section{General Fin Organization in Fish}

Fish fins fulfill key functions (e.g., during escaping from predators, capturing prey and reproduction) that directly impact fitness and, hence, are subject to strong natural and sexual selection (Fu et al., 2013; Pollux et al., 2014; Price et al., 2015). Fish fins can be grouped into single fins (i.e., dorsal, anal and caudal fin) and paired fins (i.e., pectoral and pelvic fins) (Figure 2). Fins are supported in the basal segment by an endoskeleton. Typically, this endoskeleton in paired fins consists of vertebra-independent skeletal muscle and bones, called proximal radials, arranged side by side along the anterior-posterior axis, followed by small nodular distal radials (Figure 2). In contrast, the endoskeleton of the single fins is coupled directly to bones of the vertebra or via neural spines that extend from the vertebral bones. Despite these differences in the endoskeleton, in both paired and single fins the dermal skeleton is composed of several segmented rays surrounded by soft inter-ray tissue, lacking muscle and cartilage (Figure 2). During fish growth, the dermal skeleton increases in length through the addition of new segments in the most distal part of the fin, which initially forms as a thin and soft tissue that becomes thicker and mineralized as the fin increases in length 


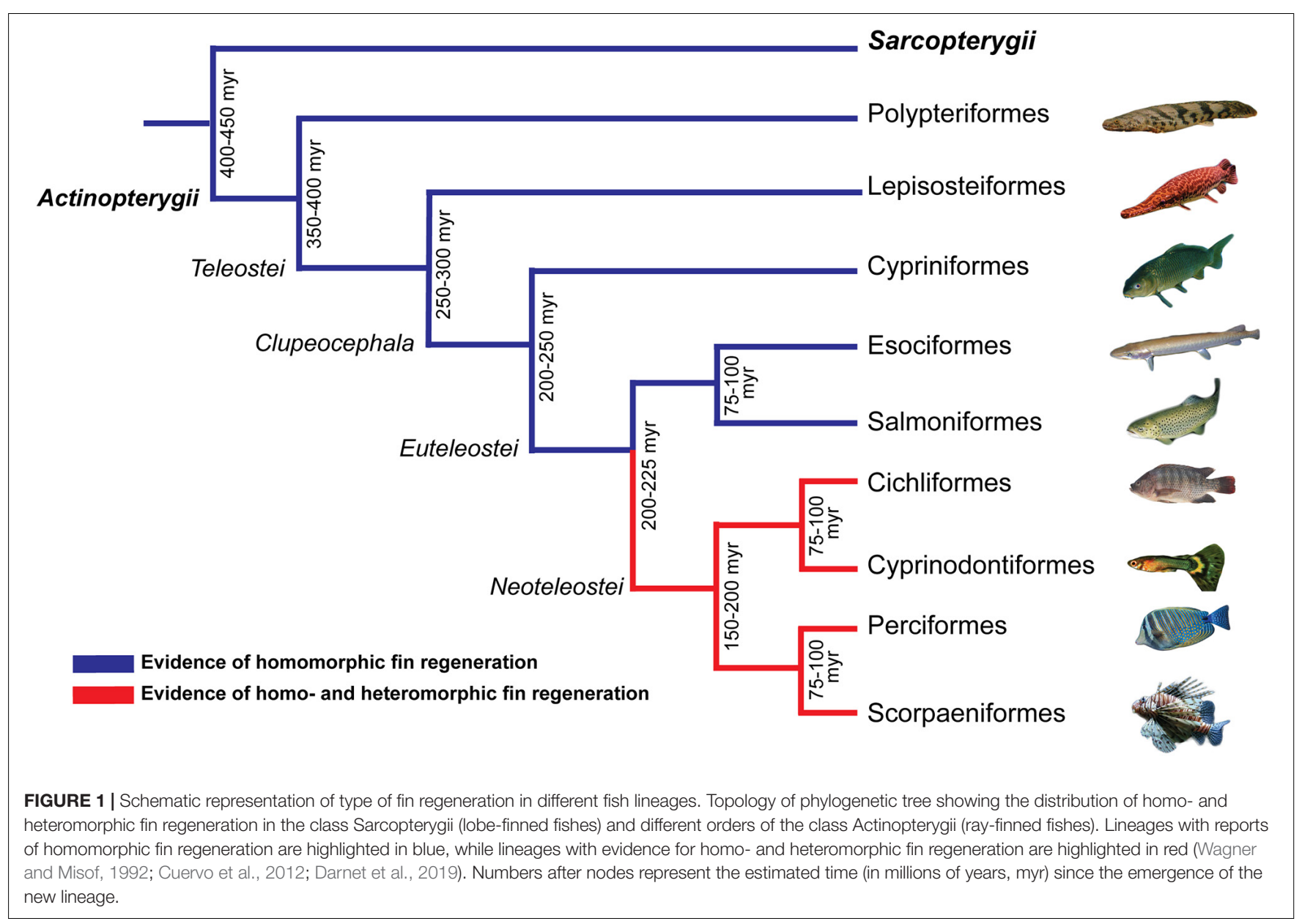

(Goldsmith et al., 2006). Remarkably, both the endoskeleton and dermal skeleton have shown regenerative capacity in fish.

\section{Endoskeleton}

Complete appendage regeneration has been observed in both lobe-finned fishes (class Sarcopterygii) and ray-finned fishes (class Actinopterygii) and recent studies suggest that these share a conserved regenerative program to repair the endoskeleton (Nogueira et al., 2016; Darnet et al., 2019). The early rayfinned Polypterus senegalus and $P$. ornatipinnis have a remarkable capacity to regenerate endoskeleton fins, showing complete regeneration within 1 month after proximal amputations (Cuervo et al., 2012). A blastema (mass of proliferating progenitor cells) is formed within 3 days post-amputation (dpa) to later give rise to a basal apical epidermis that borders the blastema in an anterior-posterior direction (Cuervo et al., 2012). This apical epidermis rapidly expands and bends toward the dorsal side, thereby giving rise to the fin fold that will develop into the endoskeleton (Cuervo et al., 2012). Cartilage differentiation is observed early in the expected bone formation area ( $9 \mathrm{dpa}$ ). A cartilaginous plate is formed, in which thickened margin predicts the differentiation of long bones, whereas radials emerge by splitting of the cartilaginous plate (Cuervo et al., 2012). Recent work has shown that other more recent ray-finned fish such as teleosts (e.g., Amatitlania nigrofasciata, Astronotus ocellatus, and Carassius auratus) can also regenerate the endoskeleton (Darnet et al., 2019).

\section{Dermal Skeleton}

Since the endoskeleton precedes dermal skeleton regeneration, one might predict that this latter capacity is a continuation of the former. However, a recent study showed that the capacity of regenerating the first does not necessarily guarantee dermal skeleton regeneration (Pápai et al., 2019), opening the possibility that different systems regulate the regeneration of both structures. The molecular mechanism underlying dermal skeleton regeneration has been extensively studied in zebrafish and its relevance and latest advances have been discussed recently by Marques et al. (2019) and Sehring and Weidinger (2020). Therefore, in this review we will only briefly describe this process. Similar to the regeneration of other appendages, dermal fin regeneration relies on a blastema to repair the lost tissue (Pfefferli and Jaźwiñska, 2015; Figure 3). Cells in the apical segment of the new and growing appendage maintain their undifferentiated stages, while blastema descendent cells differentiate into the new tissue (Pfefferli and Jaźwiñska, 2015). Therefore, a delicate balance between self-renewal and differentiation of progenitor cells is required to succeed. It has been proposed that this balance 


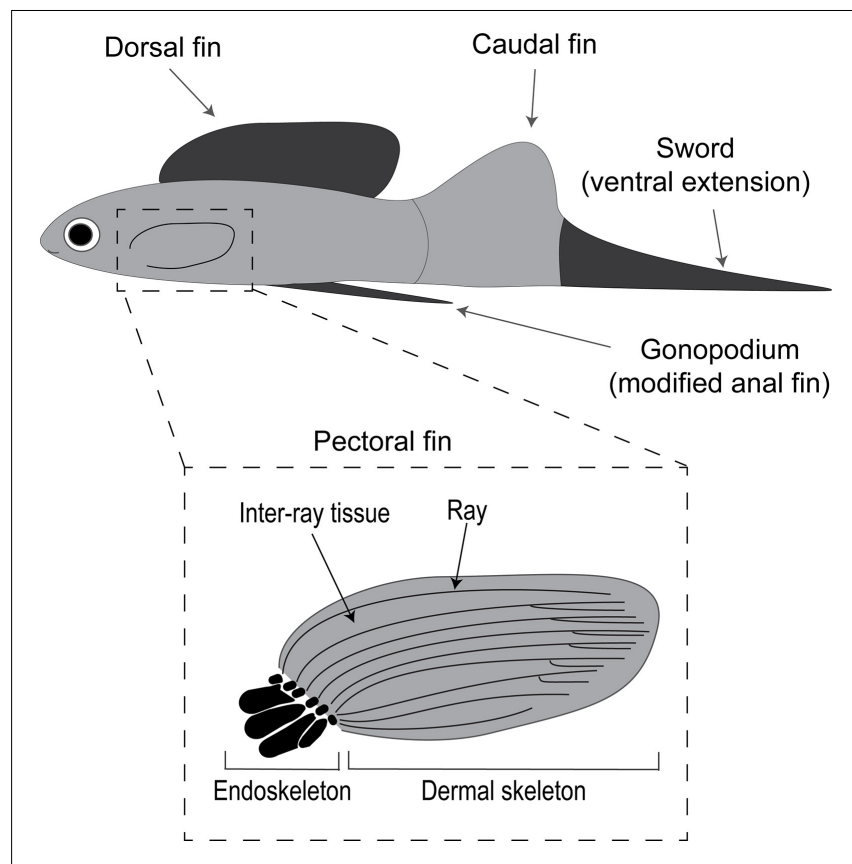

FIGURE 2 | Sexual and natural selection have driven modifications in male fin morphology and function in the fish family Poeciliidae. The different fins types include the paired pectoral fins and the single dorsal, caudal and anal (in males modified into a copulatory organ called the gonopodium) fins. The dashed square inset shows the structure of archetypical fins in Actinopterygi (ray-finned) fishes highlighting the endoskeleton (in black; only present in paired fins) and the dermal skeleton or exoskeleton (present in both paired and single fins).

is tightly regulated in the apical part of the blastema by Wnt signaling system, which coordinates blastemal cell proliferation and osteoblast maturation indirectly via downstream signals such as retinoic acid, Igf and Bmp in zebrafish (Wehner et al., 2014; Wehner and Weidinger, 2015; Figure 3).

As discussed earlier (under section "Fish fins as a model system to study regeneration" and Figure 1), in some fish groups regeneration has been reduced, showing heteromorphic fin regeneration. Yet, one other striking feature of appendage regeneration in the animal kingdom is the capacity of precisely reassembling the lost structure: i.e., giving rise to a new structure with precisely the same shape and size as the old structure after an injury (Figure 3). In zebrafish, both small wounds and major injuries, and even geometrically diverse cuts, in the fin result in a new structure that is indistinct from the old one. The predominant hypothesis to explain this process proposes that cells must evolve a positional memory, triggering the appropriate rate and extent of re-growth after injury. The remaining cells in the wound area would conserve memory and instruct how much and what type of cell programming will be required. Supporting this hypothesis, transplantation experiments of fin rays from the lobular caudal fin into a new position within the caudal fin showed that fin rays grow to reach their expected length, irrespective of the position of insertion (Shibata et al., 2018). Additionally, despite regeneration being faster in injuries close to a proximal position rather than in a distal position, both types of injuries reached the original growth length in similar time (Lee et al., 2005). The genetic and molecular mechanism controlling positional memory during fin regeneration is still unclear, but two main models have been proposed. (i) The "growth factorbase model" indicates that the levels of morphogens control fin length growth (Lee et al., 2005), while (ii) the recently proposed "niche size model" suggests that the numbers of niches harboring progenitor cells that support the blastema progressively decrease from the most proximal to the most distal part of the fins (Stewart et al., 2019). Although more work needs to be done in order to fully understand the mechanism of positional memory (Wang et al., 2019), it is clear that regenerative capacity relies on blastema cell proliferation and locally produced growth factors, which in turn can modulate the growth rate and accuracy of fin regeneration (Lee et al., 2005; Blum and Begemann, 2012; Stewart et al., 2014, 2019).

\section{HYPOTHESES FOR THE EVOLUTION OF FIN REGENERATION IN THE FISH FAMILY POECILIIDAE}

\section{The Family Poeciliidae as a Model to Study Regeneration}

The fish family Poeciliidae (order Cyprinodontiformes) is a diverse group of neotropical fish that consists of approximately 299 species in 27 genera (Lucinda, 2003). All species in the family exhibit internal fertilization and all, save for one, are viviparous (Furness et al., 2019), giving live-birth to fully developed precocial offspring (Lankheet et al., 2016). Members of this family, e.g., the guppy (Poecilia reticulata), mollies (subgenus Mollienesia), swordtails and platies (genus Xiphophorus), are commonly used in a wide variety of biological studies, ranging from cancer research and toxicology to sexual selection, life history evolution, genetics, ecology, and behavior (Ramsey et al., 2011; Pollux et al., 2014; Culumber and Tobler, 2017; Tobler et al., 2018; de Carvalho et al., 2019; McGowan et al., 2019; Thomaz et al., 2019; Hagmayer et al., 2020). This is in part because these fishes are easy to keep and breed in laboratory conditions and partly because this family provides a welldefined phylogenetic framework (Furness et al., 2019), allowing for comparative studies among closely related species with contrasting lifestyles (e.g., inhabiting different environments, displaying different forms of sexual selection, having different modes of reproduction).

The evolution of this family has been strongly marked by sexual and natural selection, resulting in great morphological and behavioral diversity evidenced by the evolution of ornamentation, specialized fins, courtship behavior and dichromatism among others (Pollux et al., 2014; Furness et al., 2019). Fins are a particularly important morphological feature fulfilling many different secondary functions that directly influence fitness (e.g., capturing prey, escaping predators, attracting mates), and as such are also subject to strong selective pressure. As a consequence, there is an extreme variation in fin size and shape within and among poeciliid species (Figure 2). Here, we argue that the regenerative capacity of fins is another, 


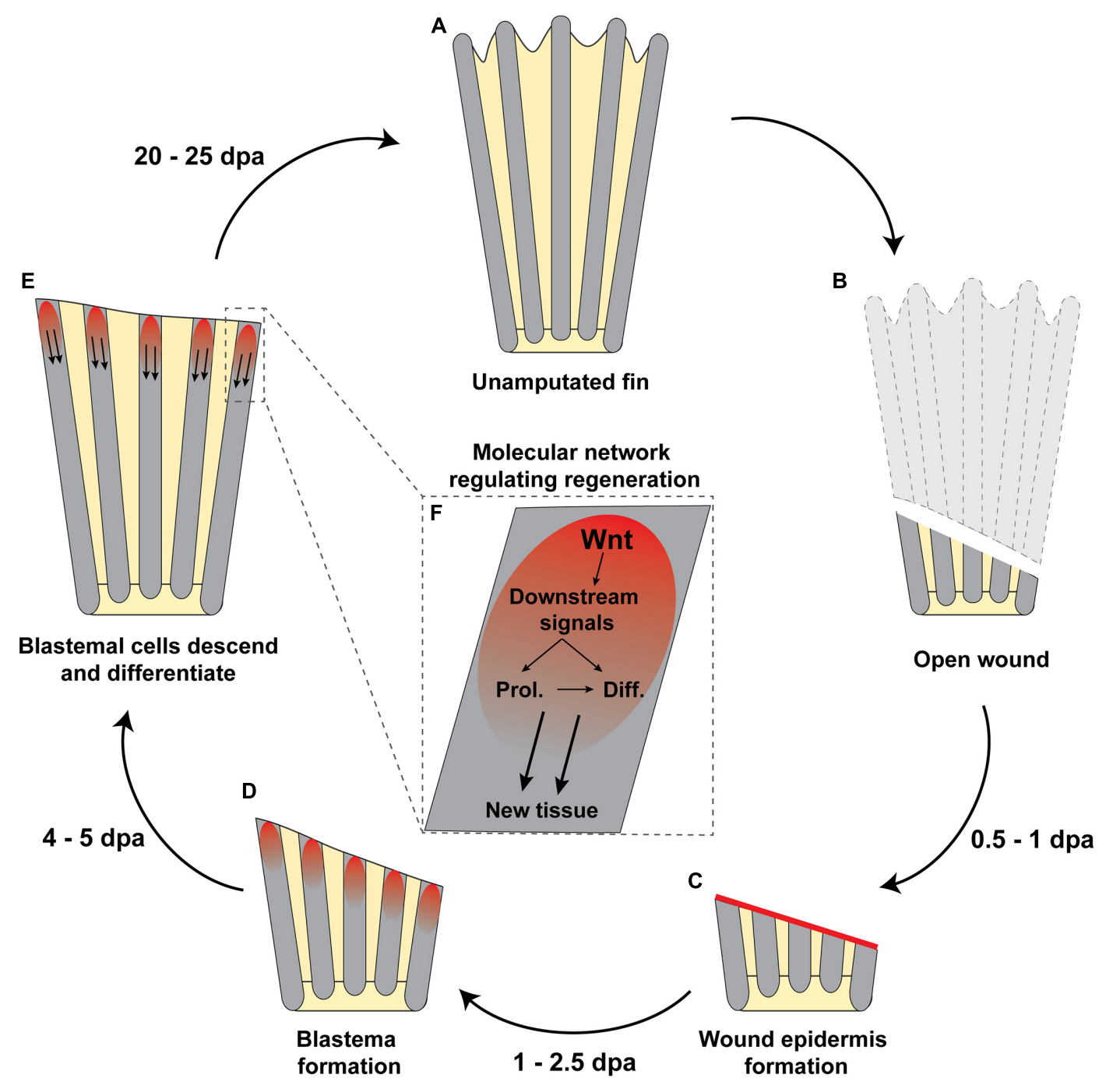

FIGURE 3 | Regeneration of the dermal skeleton in fish fins after injury. (A) Uninjured fin. (B) The regenerative process starts with an open wound from a partially amputated fin. (C) The open wound is rapidly closed by a wound epidermis (red line) within 1 day post amputation (dpa). (D) It is thought that wound epidermis initiates the blastema formation (red area in the most distal area of the fin), where (E,F) blastema cells descend upon Wnt and downstream signaling, which induce post-mitotic cells entering the cell cycle to proliferate (Prol.) and then differentiate (Diff.) to form the new tissue. (A) After 20-25 dpa, the newly regenerated fin is finished, completely reassembling the original structure. The outgrowth rate and accuracy of regeneration (homo- or heteromorphic) can vary depending on the species.

still overlooked feature of fins that is also subject to stringent natural and sexual selection. Specifically, we predict that the regenerative capability of a fin should be positively associated with its functional importance.

If true, then we expect to find significant variation in regenerative capability within or among Poeciliid species. Indeed, the few studies that have been performed to date show differences in the timing of blastema formation among Poeciliid species, ranging from 1 to 2.5 dpa (Zauner et al., 2003; Murawala et al., 2017), and full-length regeneration, ranging from 21 to $25 \mathrm{dpa}$ (Kolluru et al., 2006; Offen et al., 2008; Patel et al., 2019). However, a systematic investigation of the regenerative abilities across the Poeciliidae is not yet available. Moreover, comparative studies that juxtapose closely related species (or populations within species) inhabiting different environments (e.g., predation $v s$ predation-free environments) or displaying different mating strategies (e.g., courtship $v s$ sexual harassment) with the aim of identifying factors that drive the evolution of fin regeneration are currently lacking. In the next sections, we propose three new, empirically testable hypotheses for the evolution of fin regeneration and offer ideas for how to test these using fish from the family Poeciliidae (Figure 4).

\section{Hypothesis 1. Signaling-Driven Fin Regeneration}

Sexual selection is an important evolutionary force influencing phenotypes across the animal kingdom (Panhuis et al., 2001). 


\section{A Signaling-driven fin regeneration}
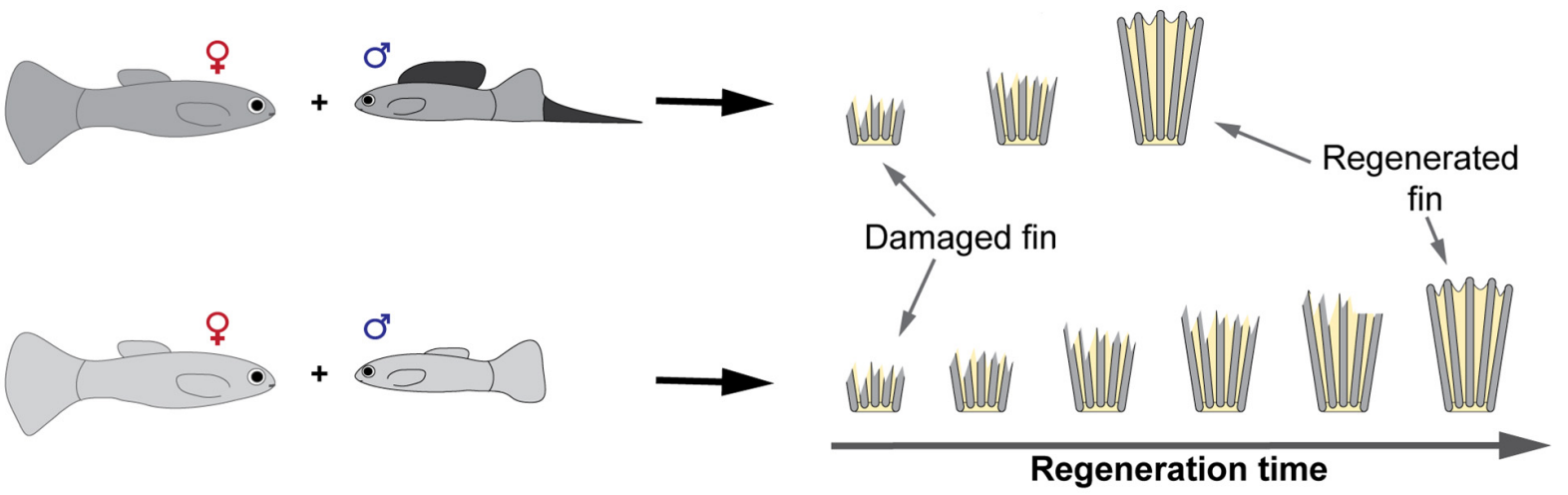

B Predation-driven fin regeneration
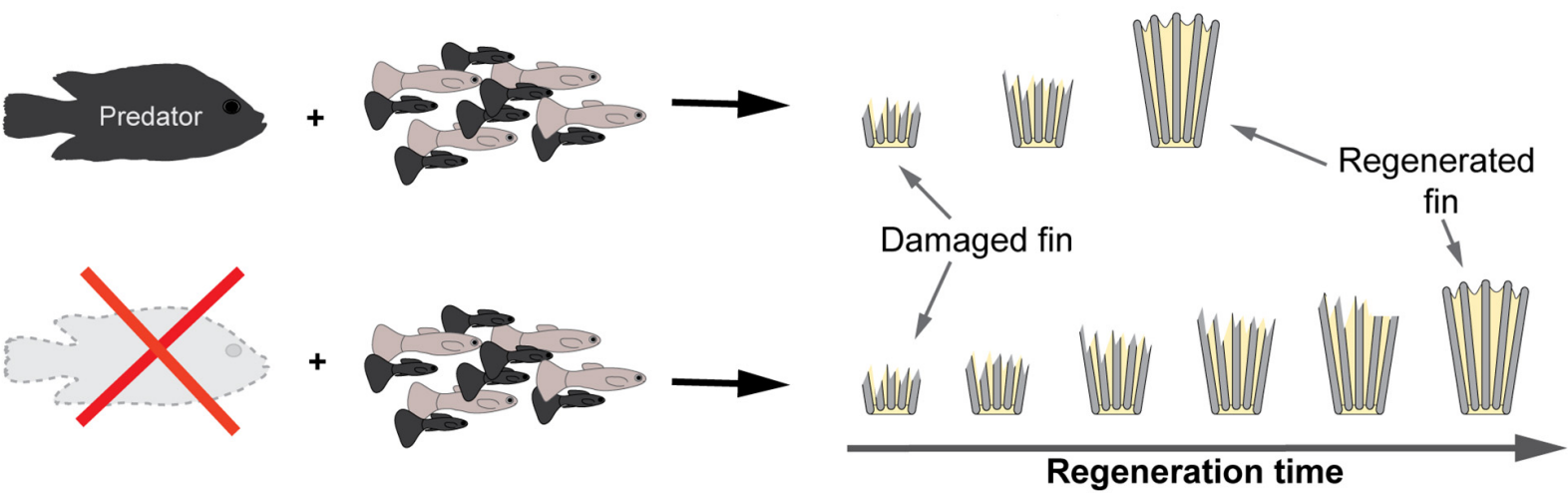

\section{c Matrotrophy-suppressed fin regeneration}
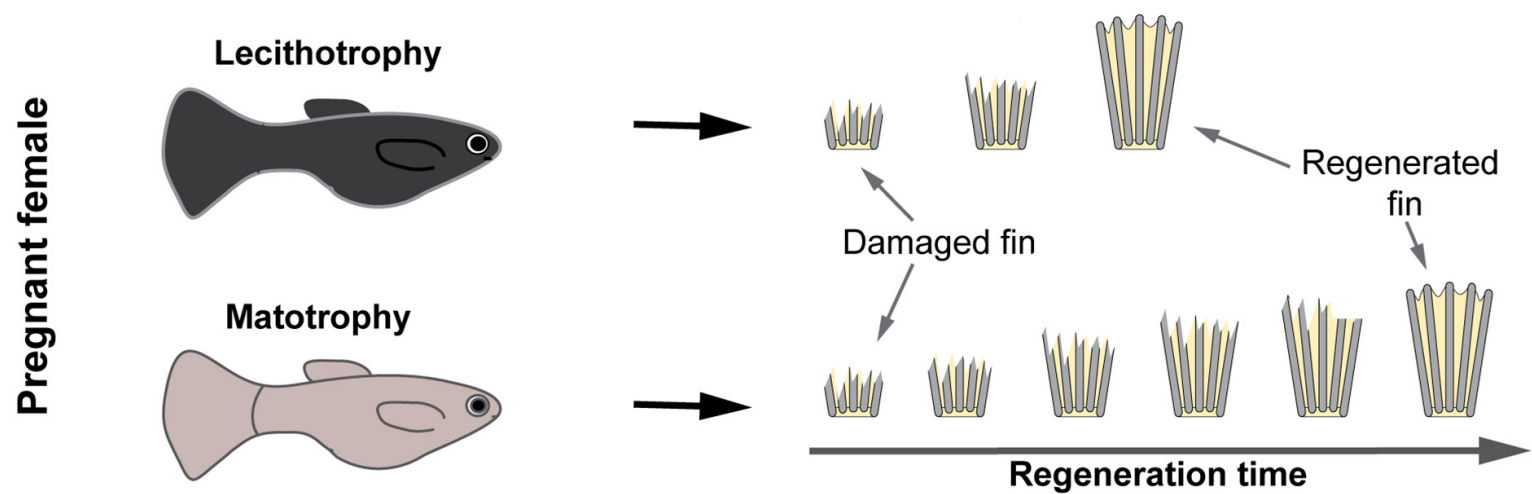

FIGURE 4 | Hypotheses for the evolution of fin regeneration in the fish family Poeciliidae. (A) If fins play an important role in precopulatory sexual selection, then they should be selected to have a faster and more accurate regeneration in males that rely in courtship. (B) If fins play an important role in predator evasion, then they should be selected to have a faster and more complete regeneration when living in a high predation environment. (C) If reproduction and regeneration enter an energetic conflict during pregnancy and a matrotrophic mode of reproduction is energetically more demanding than lecithotrophy, then matrotrophy should be associated with a suppressed female capacity for fin regeneration during gestation.

In the Poeciliidae, male phenotypic traits play an important role during precopulatory sexual selection. It is thought that sexual selection may be responsible for the extraordinary diversity of male morphological traits in this family (Pollux et al., 2014; Culumber and Tobler, 2017; Furness et al., 2019), explaining the existence and elaboration of conspicuous sexually selected traits 
(Figure 2). Fins are thought to play a particularly important role during mate selection (either during female mate choice or male-male conflict) and mating tactics in several species (Jordan et al., 2006; Kang et al., 2013; Goldberg et al., 2019). We propose that in species where fins play a key role in courtship display, sexual selection can drive the evolution of faster fin regeneration. The idea is that if a particular fin plays an important role in a species' mate selection, then that fin should have a faster and more complete (i.e., homomorphic) fin regeneration after being damaged, compared to a species in which that fin does not play a role in sexual selection (Figure 4A). Three fins in particular may be subject to this signaling-driven fin regeneration: the caudal fin (sword), dorsal fin and anal fin (gonopodium) (Figure 2).

\section{Caudal Fin}

Some males in the genus Xiphophorus develop a pigmented and elongated ventral extension of the caudal fin, forming a swordlike structure (Meyer, 1997). These species are fittingly referred to as the Swordtails. An early study showed that female Xiphophorus helleri preferred males with longer or intact fin tails over male with smaller or surgically removed portion of caudal fins (Basolo, 1990a). These results were latter supported in another study by Rosenthal and Evans (1998), in which females were presented with computer-altered videos of males, showed that courting males with intact swords were strongly preferred over courting males in which portions of the sword had been computationally erased frame-by-frame. Their study demonstrates the importance of intact swords for a male's mating success and, hence, highlights the need for a fast and accurate fin regeneration program. Given the importance of these swords in female mate choice one could argue that swordtails should have a higher regenerative capacity of the caudal fin compared to species that do not carry swords, such as the closely related platies within the genus Xiphophorus.

\section{Dorsal Fin}

The males of several Poeciliid species use a conspicuous elongated dorsal fin (Figure 2A) in erect-fin displays to females in the context of courtship behavior (Farr et al., 1986; Travis and Woodward, 1989; Ptacek and Travis, 1996; Goldberg et al., 2019) or to conspecific males as an intimidating signal during malemale conflict (Bildsøe, 1988; Benson and Basolo, 2006; Prenter et al., 2008; Goldberg et al., 2019). Recently, Goldberg et al. (2019) studied the evolution of enlongated dorsal fins in males of the subgenera Mollienesia and Limia (genus Poecilia). They argued that these ornamental dorsal fins initially emerged as a tool for male-male contests, but that they were later co-opted for male displays during courtship. Regardless of the origin, it clear that these dorsal fins are crucial for a male's mating success (Basolo, 1990b, 1995; Jordan et al., 2006). This raises the possibility that in species where the male's dorsal fin plays an important role in either courtship behavior or male-male conflict, sexual selection may have favored the evolution of a faster and more complete fin regeneration.

\section{Anal Fin}

All Poeciliid species exhibit internal fertilization, which is achieved by males inserting their intromittent organ (referred to as the gonopodium, Figure 2) into the female gonopore and releasing spermatophores (Bisazza, 1993; Greven, 2005). In some species, males use a conspicuously colored gonopodium during courtship displays (e.g., Girardinus metallicus; Kolluru et al., 2015). In other species, the length of the gonopodium is linked to alternative mating tactics, with the combination of a small body size and long gonopodium thought to facilitate sneak or coercive mating (Bisazza, 1993; Bisazza and Pilastro, 1997; Pilastro et al., 1997; Greven, 2005; Pollux et al., 2014). However, regardless of their precise role in the mating process an intact gonopodium is crucial for the successful transfer of spermatophores in every poeciliid species (Evans et al., 2011; Devigili et al., 2015; Head et al., 2017), suggesting that the regenerative capacity of the gonopodium should be equally high in all species (and all alternative mating phenotypes within species).

\section{Approaches to Test These Predictions}

The fish family Poeciliidae offers an excellent model system to test the idea that signaling driven sexual selection has led to the evolution of a faster regeneration of caudal and dorsal fins (but not gonopodia) in species where they play a key role in female mate choice. There are at least two well established approaches that can be used to test these ideas in the Poeciliidae. The first is by adopting a comparative phylogenetic approach in which species with conspicuously swords or enlarged dorsal fins used in courtship are compared to closely related species in which these fins do not play a major role in female mate choice. In particular, comparative studies with platies and swordtails in the genus Xiphophorus (Meyer, 1997; Jones et al., 2013; Kang et al., 2013), or "short-finned and sail-finned" (P. latpinna, $P$. petenensis, and $P$. velifera) species in the genus Poecilia (subgenus Mollienesia; Ptacek, 2005), could reveal interesting differences in fin regeneration among species in association with the function of these fins in courtship behavior. A second potentially powerful approach available in the Poecillidae is by comparing males within a single population that exhibit different alternative mating tactics. Many poeciliid species show intraspecific alternative mating tactics, with larger males displaying a different, often contrasting set of phenotypes and mating strategies than smaller males (Constanz, 1975; Farr et al., 1986; Ryan and Causey, 1989). Generally, larger males have a brighter coloration, more conspicuous ornamental traits (e.g., dorsal fins or swords) and courtship behavior to elicit cooperative mating, while smaller males have a drab coloration (mimicking female coloration), relatively smaller and less conspicuous ornaments and a mating system characterized by coercive or sneak mating (Farr et al., 1986; Ryan and Causey, 1989; Travis and Woodward, 1989; Ryan et al., 1992; Bisazza, 1993; Ptacek and Travis, 1996; Becker et al., 2012; Furness et al., 2020). If the dorsal fin of courters and sneakers indeed fulfills a different function, then one could argue that the larger ornamental fin of courting males should have a higher regenerative capability compared to the less conspicuous fin of sneaker males.

\section{Hypothesis 2. Predation-Driven Fin Regeneration}

The evolution of species is driven by a combination of selection pressures which vary across spatio-temporal scales shaping their morphological, physiological and behavioral traits. It has been 
argued that predation may be an important evolutionary force driving enhanced regeneration, because sublethal predation is one of the most common reasons for experiencing structural loss in nature (e.g., loss of limbs, tail, external gills, or fins). While studies in invertebrates seem to provide some support to this hypothesis (Baumiller and Gahn, 2004; Gahn and Baumiller, 2005; Berke et al., 2009), studies in vertebrates have not directly evaluated the effect of predation on the regenerative competence (e.g., regeneration rates, blastema formation and molecular mechanisms controlling this process). Studies on the lizard family Lacertidae for example have focused on the frequency of tail autotomy (i.e., self-amputation), which is an interesting phenomena that is enhanced under high predation risk (Fox et al., 1994; Pafilis et al., 2009), but the effect of predation on the subsequent regeneration of tails still remains to be evaluated.

\section{Caudal and Pectoral Fins}

In fish, swimming performance is a key component of many common activities that are directly related to fitness, such as avoiding predators, capturing prey, fighting, living in a fast-flowing environment. The fish's fins play a crucial role in steering and thrust generation during locomotion. Poeciliid fishes perform highly complex 3-dimensional escape maneuvers, which are primarily generated by the caudal peduncle and fin (Fleuren et al., 2018a,b, 2019). During fine maneuvering (e.g., while feeding or steering through a complex environment) they further rely on the synchronous use of the paired pectoral fins to control speed and direction (Lankheet et al., 2016). The importance of caudal and pectoral fins during swimming suggests that they should be subject to stringent evolutionary selection (Langerhans and Reznick, 2010; Higham et al., 2016).

\section{Predation Risk}

Predation in particular is well-known for affecting numerous behavioral, morphological and life-history traits of Poeciliid fishes (Reznick and Endler, 1982; Reznick et al., 1990, 2004; O'Steen et al., 2002; Burns et al., 2009; Kotrschal et al., 2017; Hagmayer et al., 2020) and several studies have shown that the presence of predators can influence the shape and size of the caudal peduncle and fin (Gross, 1978; Winemiller, 1990; Langerhans et al., 2004; Hendry et al., 2006; Weber et al., 2012; Price et al., 2015; Hammerschlag et al., 2018). In nature fins are frequently damaged, for example as a result of disease, predator attacks, aggressive male-male conflicts or severe floods and storms (Ziskowski et al., 2008; Sinclair et al., 2011; Furness et al., 2020). Such damages to, or loss of, fins is known to dramatically reduce the fish' escape performance, burst speed and sustained swimming ability (Webb, 1973, 1977; Plaut, 2000; Fu et al., 2013; Cai et al., 2020), likely negatively affecting its fitness in high predation environments. Given the importance of intact fins for the swimming performance of fish and hence their ability to escape from predators, we propose that predation risk may not only affect shape and size of fins, but also their regenerative capacity. Specifically, we propose that if fins play an important role in escaping predators and fin damage negatively affects the ability to escape predators, then a high predation risk should select for a faster and more complete fin regeneration (Figure 4B).

\section{Approaches to Test This Hypothesis}

To date, studies investigating a possible relationship between predation risk and fin regeneration are absent in fish. Interestingly, an early study by Broussonet (1789) reported that the caudal fin of the goldfish (Carassius auratus) regenerates faster than the ventral, pectoral and dorsal fins, which might lead one to speculate that this is related to the functional relevance of the caudal fin in swimming. Clearly, however, further studies are needed. One way in which this idea can be empirically tested in the Poeciliidae is by comparing the regenerative capacity of the different fins in poeciliid populations that have historically been exposed to different predation levels. The Trinidadian guppy (Poecilia reticulata) undoubtedly represents the best-known example of a study system that includes clearly defined natural populations that live with and without predators (e.g., Reznick, 1982, 1983; Reznick et al., 1990, 1996, 1997, 2004; Magurran, 2005; Olendorf et al., 2006), but similar "high and low predation populations" are found in many other poeciliid species, e.g., in the genera Brachyrhapis (Johnson and Belk, 2001; Johnson et al., 2009; Monterroso et al., 2014), Gambusia (Langerhans et al., 2004; Langerhans, 2009), Poeciliopsis (Hagmayer et al., 2020), and Xiphophorus (Basolo and Wagner, 2004). If predation is driving the evolution of a faster fin regeneration, then comparing wild-caught specimens and their $\mathrm{F}_{1}$ and $\mathrm{F}_{2}$ progeny in a common-garden laboratory environment will reveal consistent differences in fin regeneration as a function of predation regime and the extent to which these differences are heritable (Reznick, 1982; Reznick et al., 1990; Reznick and Bryga, 1996).

\section{Hypothesis 3. Matrotrophy-Suppressed Fin Regeneration}

Regeneration is an energetically demanding cell-based process that requires the activation of the immune system (Box $\mathbf{1}$ ), wound healing, blastema formation and, the subsequent restitution of a fully functional structure. Bely (2010) proposed that a (temporarily) reduced regenerative capacity might result from a trade-off with other fundamental processes which are equally or energetically more demanding than regeneration. Indeed, evidence suggests that the regenerative capacity can be negatively affected by other energetically expensive processes throughout the lifespan, including reproduction, one of the energetically most demanding periods in an animal's lifetime (Bernardo and Agosta, 2005; Maginnis, 2006; Seifert et al., 2012). Upon reaching sexual maturity, much of an animal's energy is often reallocated from somatic growth to reproduction (Taranger et al., 2010). The idea of a costly reproduction has led to the hypothesis that gamete production and germ cell maintenance compromise long-term somatic cell maintenance and repair (Maklakov and Immler, 2016), which means that when energy availability is limited, regeneration and 
reproduction might come in conflict with each other. Indirect support for this hypothesis comes from a recent study that found that the caudal fin of zebrafish when exposed to a challenging condition (sublethal low-dose of ionizing radiation, with genotoxic stress affecting the soma and the germline) regenerated faster in germline-free zebrafish than in germ-cell-carrying fish (Chen et al., 2020), suggesting that regeneration is curbed in individuals that produce energetically costly germ cells.

\section{Different Reproductive Modes}

The family Poeciliidae provides a unique system to study trade-offs between regenerative capacity and reproduction, by studying one of maternally most demanding reproductive periods, the pregnancy. All members of this family, except one (Tomeurus gracilis), are live-bearing fish. Moreover, several independent evolutionary transitions from lecithotrophy (a form of maternal provisioning in which nutrients are provided to the eggs before fertilization) to matroptrophy (a type of maternal provisioning in which nutrients are provided after fertilization, i.e., throughout embryonic development in utero) have occurred in this live-bearing family (Pollux et al., 2009). These transitions coincide with a shift in the timing of the allocation of maternal nutrients to the offspring from preto postfertilization. The amount of resources a female can allocate to her offspring is the result of a delicate balance between maternal energy uptake (via feeding), her own caloric utilization (maintenance) and the amount of excess energy that is subsequently available for other functions such as reproduction and/or regeneration (e.g., Reznick et al., 1996; Trexler, 1997; Banet et al., 2010; Pollux and Reznick, 2011; Hagmayer et al., 2018).

In poeciliids, a pregnancy may impose high energetic demands on females, due to: (i) the physical burden of having to propel an increasingly larger body volume and higher body mass through the water during locomotion (Plaut, 2002; Ghalambor et al., 2004; Fleuren et al., 2018b, 2019; Quicazan-Rubio et al., 2019) and (ii) the physiological burden of having to provide oxygen and, in some species, nutrients to the developing offspring. This physiological burden, however, is not equal for all Poeciliid species and may differ greatly depending on their mode of maternal provisioning. Specifically, the energy requirements during pregnancy are significantly higher for matrotrophic species compared to lecithotrophic ones, because of the additional energy costs of having to: (i) nourish their developing embryos, i.e., the acquirement, consumption, digestion and absorption of additional food plus the subsequent transport of converted nutrients to the embryos, and (ii) develop a very costly tissue, i.e., the placenta, that regulates many complex and energetically expensive immunological and endocrine maternal-fetal interactions (Pollux et al., 2009). One could argue that the higher energetic demands associated with placentation, a special form of matrotrophy found in the Poeciliidae in which the female transfers nutrient to the fetus in utero via a placenta, make it more likely that females experience conflicting demands between maintenance, reproduction and regeneration during pregnancy. We therefore posit that the mode of maternal provisioning should influence a female's regenerative capacity during gestation. Specifically, we propose that since (i) the pregnancy is energetically more demanding in matrotrophic than lecithotrophic females and (ii) matrotrophic provisioning and regeneration are both very costly processes, matrotrophy should be associated with a suppressed female capacity for fin regeneration during gestation (Figure 4C).

\section{Approaches to Test This Hypothesis}

There is a well-supported phylogenetic framework for the evolution of the placenta in the Poeciliidae that can be used for comparative studies on lecithotrophic and matrotrophic species to test these predictions (Pollux et al., 2014; Furness et al., 2019). These studies show that (1) the placenta independently evolved multiple times in this family and (2) that there are closely related species that either lack a placenta or have intermediate stages in the evolution of the placenta. This remarkable diversity allows for the selection of closely related species, particularly in the genus Poecilia (Meredith et al., 2010, 2011) and Poeciliopsis (Reznick et al., 2002), for comparative experimental studies that address fundamental questions about how female fin regeneration during pregnancy co-evolves with the evolution of the placenta. Future studies should optimally look for differences in fin regeneration throughout a female's reproductive cycle, i.e., prior to sexual maturation and egg fertilization, during pregnancy and after parturition, between lecithotrophic and placental matrotrophic females. These studies will shed new light on the factors that could potentially limit the regenerative competence of species.

\section{CONCLUSION}

Important progress has been made on understanding the cellular and molecular mechanisms underlying appendage regeneration. Unfortunately, however, most of these insights are based on only a few model species (e.g., the Zebrafish). Moreover, many fundamental questions regarding why or how regeneration evolved remain poorly understood. Future studies should therefore include new animal models and compare species that may have evolved divergent regenerative capacities in response to different selection pressures. Here, we propose 3 novel hypotheses for the evolution of fin regeneration in fishes and argue that the fish family Poeciliidae offers an interesting new study system for comparative studies at different phylogenetic levels (among species, among populations within species and among individuals within populations) to empirically test these hypotheses. Such comparative studies in the fish family Poeciliidae may help identify the factors that drive or influence the evolution of regeneration and help elucidate the underlaying mechanisms of evolution (e.g., changes in the cellular processes, gene expression, molecular pathways, immunology). The era of next-generation sequencing and the recent advances in genome research in the Poeciliidae (Schartl et al., 2013; Kunstner et al., 2016; Shen et al., 2016; Warren et al., 2018; Mateos et al., 2019; Van Kruistum et al., 2019, 2020) add further to the appeal of this family. 


\section{AUTHOR CONTRIBUTIONS}

DS drafted the manuscript and design the figures. GW and BP contributed to content and editing of the manuscript and figures. All authors contributed to the article and approved the submitted version.

\section{REFERENCES}

Alibardi, L. (2017). Biological and molecular differences between tail regeneration and limb scarring in lizard: an inspiring model addressing limb regeneration in amniotes. J. Exp. Zool. B Mol. Dev. Evol. 328, 493-514. doi: 10.1002/jez.b.22754

Alibardi, L., and Toni, M. (2005). Wound keratins in the regenerating epidermis of lizard suggest that the wound reaction is similar in the tail and limb. J. Exp. Zool. A Comp. Exp. Biol. 303, 845-860. doi: 10.1002/jez.a.213

Banet, A. I., Au, A. G., and Reznick, D. N. (2010). Is mom in charge? Implications of resource provisioning on the evolution of the placenta. Evolution 64, 31723182.

Basolo, A. L. (1990a). Female preference for male sword length in the green swordtail, Xiphophorus helleri (Pisces: Poeciliidae). Anim. Behav. 40, 332-338. doi: 10.1016/S0003-3472(05)80928-5

Basolo, A. L. (1990b). Female preference predates the evolution of the sword in swordtail fish. Science 250, 808-810. doi: 10.1126/science.250.4982.808

Basolo, A. L. (1995). A further examination of a pre-existing bias favouring a sword in the genusXiphophorus. Anim. Behav. 50, 365-375. doi: 10.1006/anbe.1995. 0252

Basolo, A. L., and Wagner, W. E. (2004). Covariation between predation risk, body size and fin elaboration in the green swordtail, Xiphophorus helleri. Biol. J. Linn. Soc. Lond. 83, 87-100. doi: 10.1111/j.1095-8312.2004.00369.x

Baumiller, T. K., and Gahn, F. J. (2004). Testing predator-driven evolution with Paleozoic crinoid arm regeneration. Science 305, 1453-1455. doi: 10.1126/ science. 1101009

Becker, L. J., Aspbury, A. S., and Gabor, C. R. (2012). Body size dependent male sexual behavior in a natural population of sailfin mollies (Poecilia latipinna). Am. Midl. Nat. 167, 366-372. doi: 10.1674/0003-0031-167.2.366

Bely, A. E. (2010). Evolutionary loss of animal regeneration: pattern and process. Integr. Comp. Biol. 50, 515-527. doi: 10.1093/icb/icq118

Bely, A. E., and Nyberg, K. G. (2010). Evolution of animal regeneration: reemergence of a field. Trends Ecol. Evol. 25, 161-170. doi: 10.1016/j.tree.2009. 08.005

Benson, K. E., and Basolo, A. L. (2006). Male-male competition and the sword in male swordtails, Xiphophorus helleri. Anim. Behav. 71, 129-134. doi: 10.1016/j. anbehav.2005.05.004

Berke, S. K., Cruz, V., and Osman, R. W. (2009). Sublethal predation and regeneration in two onuphid polychaetes: patterns and implications. Biol. Bull. 217, 242-252. doi: 10.1086/BBLv217n3p242

Bernardo, J., and Agosta, S. J. (2005). Evolutionary implications of hierarchical impacts of nonlethal injury on reproduction, including maternal effects. Biol. J. Linn. Soc. Lond. 86, 309-331. doi: 10.1111/j.1095-8312.2005.00532.x

Bildsøe, M. (1988). Aggressive, sexual, and foraging behaviour in Poecilia velifera (Pisces: Poeciliidae) during captivity. Ethology 79, 1-12. doi: 10.1111/j.14390310.1988.tb00695.x

Bisazza, A. (1993). Male competition, female mate choice and sexual size dimorphism in poeciliid fishes. Mar. Behav. Physiol. 23, 257-286. doi: 10.1080/ 10236249309378869

Bisazza, A., and Pilastro, A. (1997). Small male mating advantage and reversed size dimorphism in poeciliid fishes. J. Fish Biol. 50, 397-406. doi: 10.1006/jfbi.1996. 0303

Blum, N., and Begemann, G. (2012). Retinoic acid signaling controls the formation, proliferation and survival of the blastema during adult zebrafish fin regeneration. Development 139, 107-116. doi: 10.1242/dev.065391

Broussonet, P. M. A. (1789). Memoir on the regeneration of certain parts of the bodies of fishes. Lit. Mag. Br. 3, 111-113. doi: 10.5962/bhl.title.5761

Burns, J. G., Di Nardo, P., and Rodd, F. H. (2009). The role of predation in variation in body shape in guppies Poecilia reticulata: a comparison of field and common

\section{FUNDING}

This work was supported by a scholarship from ANID Chile awarded to DS and a VIDI grant (864.14.008) from the Netherlands Organization for Scientific Research awarded to BP.

garden phenotypes. J. Fish Biol. 75, 1144-1157. doi: 10.1111/j.1095-8649.2009. 02314.x

Cai, L., Chen, J., Johnson, D., Tu, Z., and Huang, Y. (2020). Effect of tail fin loss on swimming capability and tail beat frequency of juvenile black carp mylopharyngodon piceus. Aquat. Biol. 29, 71-77. doi: 10.3354/ab0 0727

Cary, G. A., Wolff, A., Zueva, O., Pattinato, J., and Hinman, V. F. (2019). Analysis of sea star larval regeneration reveals conserved processes of whole-body regeneration across the metazoa. BMC Biol. 17:16. doi: 10.1186/s12915-0190633-9

Chen, H., Jolly, C., Bublys, K., Marcu, D., and Immler, S. (2020). Trade-off between somatic and germline repair in a vertebrate supports the expensive germ line hypothesis. Proc. Natl. Acad. Sci. U. S. A. 117, 8973-8979. doi: 10.1073/pnas. 1918205117

Constanz, G. (1975). Behavioral ecology of mating in the male gila topminnow, poecilipsis occidentalis (Cyprinodontiformes: Poeciliidae). Ecology 56, 966973.

Cuervo, R., Hernández-Martínez, R., Chimal-Monroy, J., Merchant-Larios, H., and Covarrubias, L. (2012). Full regeneration of the tribasal Polypterus fin. Proc. Natl. Acad. Sci. U. S. A. 109, 3838-3843. doi: 10.1073/pnas.1006619109

Culumber, Z. W., and Tobler, M. (2017). Sex-specific evolution during the diversification of live-bearing fishes. Nat. Ecol. Evol. 1, 1185-1191. doi: 10.1038/ s41559-017-0233-4

Darnet, S., Dragalzewa, A., Amaral, D. B., Sousa, J., Thompson, A. W., Cass, A., et al. (2019). Deep evolutionary origin of limb and fin regeneration. Proc. Natl. Acad. Sci. U. S. A. 116, 15106-15115. doi: 10.1073/pnas.1900475116

de Carvalho, D. R., Flecker, A. S., Alves, C. B. M., Sparks, J. P., and Pompeu, P. S. (2019). Trophic responses to aquatic pollution of native and exotic livebearer fishes. Sci. Total Environ. 681, 503-515. doi: 10.1016/j.scitotenv.2019.05.092

Devigili, A., Evans, J. P., Di Nisio, A., and Pilastro, A. (2015). Multivariate selection drives concordant patterns of pre- and postcopulatory sexual selection in a livebearing fish. Nat. Commun. 6:8291. doi: 10.1038/ncomms9291

Evans, J. P., Gasparini, C., Holwell, G. I., Ramnarine, I. W., Pitcher, T. E., and Pilastro, A. (2011). Intraspecific evidence from guppies for correlated patterns of male and female genital trait diversification. Proc. Biol. Sci. 278, 2611-2620. doi: $10.1098 / \mathrm{rspb} .2010 .2453$

Farr, J. A., Travis, J., and Trexler, J. C. (1986). Behavioural allometry and interdemic variation in sexual behaviour of the sailfin molly, Poecilia latipinna (Pisces: Poeciliidae). Anim. Behav. 34, 497-509. doi: 10.1016/S0003-3472(86)80118-X

Fleuren, M., Quicazan-Rubio, E. M., van Leeuwen, J. L., and Pollux, B. J. A. (2018a). Why do placentas evolve? Evidence for a morphological advantage during pregnancy in live-bearing fish. PLoS One 13:e0195976. doi: 10.1371/journal. pone.0195976

Fleuren, M., Van Leeuwen, J. L., and Pollux, B. J. A. (2019). Superfetation reduces the negative effects of pregnancy on the fast-start escape performance in live-bearing fish. Proc. Biol. Sci. 286:20192245. doi: 10.1098/rspb.2019.2245

Fleuren, M., Van Leeuwen, J. L., Quicazan-Rubio, E. M., Pieters, R., Pollux, B. J., and Voesenek, C. J. (2018b). Three-dimensional analysis of the fast-start escape response of the least killifish, Heterandria formosa. J. Exp. Biol. 221:jeb168609. doi: $10.1242 /$ jeb.168609

Fox, D. T., Cohen, E., and Smith-Bolton, R. (2020). Model systems for regeneration: Drosophila. Development 147:dev173781. doi: 10.1242/dev.173781

Fox, S., Perea-Fox, S., and Castro Franco, R. (1994). Development of the tail autotomy adaptation in lizards under disparate levels of predation at high and low elevations in Mexico. Southwest. Nat. 39, 311-322.

Fu, C., Cao, Z. D., and Fu, S. J. (2013). The effects of caudal fin loss and regeneration on the swimming performance of three cyprinid fish species with different swimming capacities. J. Exp. Biol. 216, 3164-3174. doi: 10.1242/jeb.084244 
Furness, A. I., Hagmayer, A., and Pollux, B. J. A. (2020). Size-dependent male mating tactics and their morphological correlates in Poecilia gillii. Biol. J. Linn. Soc. Lond. 131, 880-897

Furness, A. I., Pollux, B. J. A., Meredith, R. W., Springer, M. S., and Reznick, D. N. (2019). How conflict shapes evolution in poeciliid fishes. Nat. Commun. 10:3335. doi: 10.1038/s41467-019-11307-5

Gahn, F. J., and Baumiller, T. K. (2005). Paleontological society arm regeneration in mississippian crinoids: evidence of intense predation pressure in the Paleozoic? Paleobiology 31, 151-164.

Galis, F., Metz, J. A. J., and van Alphen, J. J. M. (2018). Development and evolutionary constraints in animals. Annu. Rev. Ecol. Evol. Syst. 49, 499-522. doi: 10.1146/annurev-ecolsys-110617-062339

Galis, F., Wagner, G. P., and Jockusch, E. L. (2003). Why is limb regeneration possible in amphibians but not in reptiles, birds, and mammals? Evol. Dev. 5, 208-220. doi: 10.1046/j.1525-142X.2003.03028.x

Galliot, B., Crescenzi, M., Jacinto, A., and Tajbakhsh, S. (2017). Trends in tissue repair and regeneration. Development 144, 357-364. doi: 10.1242/dev.14 4279

Gemberling, M., Bailey, T. J., Hyde, D. R., and Poss, K. D. (2013). The zebrafish as a model for complex tissue regeneration. Trends Genet. 29, 611-620. doi: 10.1016/j.tig.2013.07.003

Ghalambor, C. K., Reznick, D. N., and Walker, J. A. (2004). Constraints on adaptive evolution: the functional trade-off between reproduction and fast-start swimming performance in the Trinidadian guppy (Poecilia reticulata). Am. Nat. 164, 38-50. doi: 10.1086/421412

Ghosh, S., Roy, S., Séguin, C., Bryant, S. V., and Gardiner, D. M. (2008). Analysis of the expression and function of Wnt-5a and Wnt-5b in developing and regenerating axolotl (Ambystoma mexicanum) limbs. Dev. Growth Differ. 50, 289-297. doi: 10.1111/j.1440-169X.2008.01000.x

Godwin, J. W., Pinto, A. R., and Rosenthal, N. A. (2013). Macrophages are required for adult salamander limb regeneration. Proc. Natl. Acad. Sci. U. S. A. 110, 9415-9420. doi: 10.1073/pnas.1300290110

Goldberg, D. L., Landy, J. A., Travis, J., Springer, M. S., and Reznick, D. N. (2019). In love and war: the morphometric and phylogenetic basis of ornamentation, and the evolution of male display behavior, in the livebearer genus Poecilia. Evolution 7, 360-377. doi: 10.1111/evo.13671

Goldsmith, M. I., Iovine, M. K., O’Reilly-Pol, T., and Johnson, S. L. (2006). A developmental transition in growth control during zebrafish caudal fin development. Dev. Biol. 296, 450-457. doi: 10.1016/j.ydbio.2006.06.010

Greven, H. (2005). "Structural and behavioral traits associated with sperm transfer in Poeciliinae," in Viviparous Fishes, eds M. C. Uribe and H. J. Grier (Homestead, FL: New Life Publications), 147-166.

Gross, H. P. (1978). Natural selection by predators on the defensive apparatus of the three-spined stickleback, Gasterosteus aculeatus L. Can. J. Zool. 56, 398-413. doi: 10.1139/z78-058

Hagmayer, A., Furness, A. I., Reznick, D. N., Dekker, M. L., and Pollux, B. J. A. (2020). Predation risk shapes the degree of placentation in natural populations of live-bearing fish. Ecol. Lett. 23, 831-840. doi: 10.1111/ele.13487

Hagmayer, A., Furness, A. I., Reznick, D. N., and Pollux, B. J. A. (2018). Maternal size and body condition predict the amount of post-fertilization maternal provisioning in matrotrophic fish. Ecol. Evol. 8, 12386-12396. doi: 10.1002/ece3. 4542

Hammerschlag, N., Barley, S. C., Irschick, D. J., Meeuwig, J. J., Nelson, E. R., and Meekan, M. G. (2018). Predator declines and morphological changes in prey: evidence from coral reefs depleted of sharks. Mar. Ecol. Prog. Ser. 586, 127-139. doi: 10.3354/meps 12426

Hasegawa, T., Hall, C. J., Crosier, P. S., Abe, G., Kawakami, K., Kudo, A., et al. (2017). Transient inflammatory response mediated by interleukin-1 $\beta$ is required for proper regeneration in zebrafish fin fold. Elife 6:e22716. doi: 10 . 7554/eLife. 22716

Head, M. L., Kahn, A. T., Henshaw, J. M., Keogh, J. S., and Jennions, M. D. (2017). Sexual selection on male body size, genital length and heterozygosity: consistency across habitats and social settings. J. Anim. Ecol. 86, 1458-1468. doi: 10.1111/1365-2656.12742

Hendry, A. P., Kelly, M. L., Kinnison, M. T., and Reznick, D. N. (2006). Parallel evolution of the sexes? Effects of predation and habitat features on the size and shape of wild guppies. J. Evol. Biol. 19, 741-754. doi: 10.1111/j.1420-9101.2005. 01061.x
Higham, T. E., Rogers, S. M., Langerhans, R. B., Jamniczky, H. A., Lauder, G. V., Stewart, W. J., et al. (2016). Speciation through the lens of biomechanics: locomotion, prey capture and reproductive isolation. Proc. Biol. Soc. 283:20161294. doi: 10.1098/rspb.2016.1294

Hirose, K., Payumo, A. Y., Cutie, S., Hoang, A., Zhang, H., Guyot, R., et al. (2019). Evidence for hormonal control of heart regenerative capacity during endothermy acquisition. Science 364, 184-188.

Hughes, L. C., Ortí, G., Huang, Y., Sun, Y., Baldwin, C. C., Thompson, A. W., et al. (2018). Comprehensive phylogeny of ray-finned fishes (Actinopterygii) based on transcriptomic and genomic data. Proc. Natl. Acad. Sci. U. S. A. 115, 6249-6254. doi: 10.1073/pnas.1719358115

Hui, S. P., Sheng, D. Z., Sugimoto, K., Gonzalez-Rajal, A., Nakagawa, S., Hesselson, D., et al. (2017). Zebrafish regulatory T cells mediate organ-specific regenerative programs. Dev. Cell. 43, 659-672.e5. doi: 10.1016/j.devcel.2017.11.010

Ivankovic, M., Haneckova, R., Thommen, A., Grohme, M. A., Vila-Farré, M., Werner, S., et al. (2019). Model systems for regeneration: planarians. Development 146:dev167684. doi: 10.1242/dev.167684

Johnson, J. B., and Belk, M. C. (2001). Predation environment predicts divergent life-history phenotypes among populations of the livebearing fish Brachyrhaphis rhabdophora. Oecologia 126, 142-149. doi: 10.1007/s004420000504

Johnson, J. B., Zúñiga-vega, J. J., Johnson, J. B., and Jaime, J. Z. (2009). Differential mortality drives life-history evolution and population dynamics in the fish Brachyrhaphis rhabdophora. Ecology 90, 2243-2252.

Jones, J. C., Fan, S., Franchini, P., Schartl, M., and Meyer, A. (2013). The evolutionary history of Xiphophorus fish and their sexually selected sword: a genome-wide approach using restriction site-associated DNA sequencing. Mol. Ecol. 22, 2986-3001. doi: 10.1111/mec.12269

Jordan, R., Howe, D., Knight, T., and Gould, J. (2006). Female choice linked to male dorsal fin height in a shortfin molly. J. Ethol. 24, 301-304. doi: 10.1007/s10164006-0196-4

Josefowicz, S. Z., Lu, L. F., and Rudensky, A. Y. (2012). Regulatory T cells: mechanisms of differentiation and function. Annu. Rev. Immunol. 30, 531-564. doi: 10.1146/annurev.immunol.25.022106.141623

Joven, A., Elewa, A., and Simon, A. (2019). Model systems for regeneration: salamanders. Development 146:dev167700. doi: 10.1242/dev.167700

Julier, Z., Park, A. J., Briquez, P. S., and Martino, M. M. (2017). Promoting tissue regeneration by modulating the immune system. Acta Biomater. 53, 13-28. doi: 10.1016/j.actbio.2017.01.056

Kang, J. H., Schartl, M., Walter, R. B., and Meyer, A. (2013). Comprehensive phylogenetic analysis of all species of swordtails and platies (Pisces: Genus Xiphophorus) uncovers a hybrid origin of a swordtail fish, Xiphophorus monticolus, and demonstrates that the sexually selected sword originated in the ancestral lineage of the genus, but was lost again secondarily. BMC Evol. Biol. 13:25. doi: 10.1186/1471-2148-13-25

Kolluru, G. R., Castillo, C., Hendrickson, M., Hughes, M., Krause, P., LePiane, K., et al. (2015). Sexual selection in black morph Girardinus metallicus (Pisces: Poeciliidae): females can spot a winner (but we cannot). Ethology 121, 12121224. doi: 10.1111/eth.12434

Kolluru, G. R., Ruiz, N. C., Del Cid, N., Dunlop, E., and Grether, G. F. (2006). The effects of carotenoid and food intake on caudal fin regeneration in male guppies. J. Fish Biol. 68, 1002-1012. doi: 10.1111/j.0022-1112.2006.00976.x

Kotrschal, A., Deacon, A. E., Magurran, A. E., and Kolm, N. (2017). Predation pressure shapes brain anatomy in the wild. Evol. Ecol. 31, 619-633. doi: 10.1007/ s10682-017-9901-8

Kunstner, A., Hoffmann, M., Fraser, B. A., Kottler, V. A., Sharma, E., Weigel, D., et al. (2016). The genome of the trinidadian guppy, Poecilia reticulata, and variation in the Guanapo population. PLoS One 11:e0169087. doi: 10.1371/ journal.pone.0169087

Langerhans, R. B. (2009). Trade-off between steady and unsteady swimming underlies predator-driven divergence in Gambusia affinis. J. Evol. Biol. 22, 1057-1075. doi: 10.1111/j.1420-9101.2009.01716.x

Langerhans, R. B., Layman, C. A., Shokrollahi, A. M., and Dewitt, T. J. (2004). Predator-driven phenotypic diversification in Gambusia affinis. Evolution 58, 2305-2318. doi: 10.1111/j.0014-3820.2004.tb01605.x

Langerhans, R. B., and Reznick, D. N. (2010). "Ecology and evolution of swimming performance in fishes: predicting evolution with biomechanics," in Fish Locomotion: An Eco-Ethological Perspective, eds P. Domenici and B. G. Kapoor (Oxford: Oxford Press), 200-248. doi: 10.1201/b10190-7 
Lankheet, M. J., Stoffers, T., van Leeuwen, J. L., and Pollux, B. J. A. (2016). Acquired versus innate prey capturing skills in super-precocial live-bearing fish. Proc. Biol. Sci. 283:20160972. doi: 10.1098/rspb.2016.0972

Lee, Y., Grill, S., Sanchez, A., Murphy-Ryan, M., and Poss, K. D. (2005). Fof signaling instructs position-dependent growth rate during zebrafish fin regeneration. Development 132, 5173-5183. doi: 10.1242/dev.02101

Leigh, N. D., Dunlap, G. S., Johnson, K., Mariano, R., Oshiro, R., Wong, A. Y., et al. (2018). Transcriptomic landscape of the blastema niche in regenerating adult axolotl limbs at single-cell resolution. Nat. Commun. 9:5153. doi: 10.1038/ s41467-018-07604-0

Li, L., Yan, B., Shi, Y. Q., Zhang, W. Q., and Wen, Z. L. (2012). Live imaging reveals differing roles of macrophages and neutrophils during zebrafish tail fin regeneration. J. Biol. Chem. 287, 25353-25360. doi: 10.1074/jbc.M112.349126

Lucinda, P. H. F. (2003). "Family Poeciliidae (Livebearers)," in Check List of the Freshwater Fishes of South and Central America, eds R. E. Reis, S. O. Kullander, and J. J. Ferraris (Porto Alegre: EDIPUCRS), 555-581.

Maden, M., and Varholick, J. A. (2020). Model systems for regeneration: the spiny mouse, Acomys cahirinus. Development 147:dev167718. doi: 10.1242/dev. 167718

Maginnis, T. L. (2006). The costs of autotomy and regeneration in animals: a review and framework for future research. Behav. Ecol. 17, 857-872. doi: 10. 1093/beheco/arl010

Magurran, A. E. (2005). Evolutionary Ecology: The Trinidadian Guppy. Oxford Series in Ecology and Evolution. New York, NY: Oxford University Press

Maklakov, A. A., and Immler, S. (2016). The expensive germline and the evolution of ageing. Curr. Biol. 26, R577-R586. doi: 10.1016/j.cub.2016.04.012

Mao, A. S., and Mooney, D. J. (2015). Regenerative medicine: current therapies and future directions. Proc. Natl. Acad. Sci. U. S. A. 112, 14452-14459. doi: 10.1073/pnas. 1508520112

Marques, I., Lupi, E., and Mercader, N. (2019). Model systems for regeneration: zebrafish. Development 146:dev167700.

Martin, P., and Parkhurst, S. M. (2004). Parallels between tissue repair and embryo morphogenesis. Development 131, 3021-3034. doi: 10.1242/dev.01253

Mateos, M., Kang, D., Klopp, C., Parrinello, H., Garcia, M., Schumer, M., et al. (2019). Draft genome assembly and annotation of the gila topminnow Poeciliopsis occidentalis. Front. Ecol. Evol. 7:404. doi: 10.3389/fevo.2019.00404

McGowan, K. L., Passow, C. N., Arias-Rodriguez, L., Tobler, M., and Kelley, J. L. (2019). Expression analyses of cave mollies (Poecilia mexicana) reveal key genes involved in the early evolution of eye regression. Biol. Lett. 15:20190554. doi: 10.1098/rsbl.2019.0554

Meredith, R. W., Pires, M. N., Reznick, D. N., and Springer, M. S. (2010). Molecular phylogenetic relationships and the evolution of the placenta in Poecilia (Micropoecilia) (Poeciliidae: Cyprinodontiformes). Mol. Phylogenet. Evol. 55, 631-639. doi: 10.1016/j.ympev.2009.11.006

Meredith, R. W., Pires, M. N., Reznick, D. N., and Springer, M. S. (2011). Molecular phylogenetic relationships and the coevolution of placentotrophy and superfetation in Poecilia (Poeciliidae: Cyprinodontiformes). Mol. Phylogenet. Evol. 59, 148-157. doi: 10.1016/j.ympev.2011.01.014

Meyer, A. (1997). The evolution of sexually selected traits in male swordtail fishes (Xiphophorus: Poeciliidae). Heredity 79, 329-337. doi: 10.1038/hdy.1997.161

Miskolci, V., Squirrell, J., Rindy, J., Vincent, W., Sauer, J. D., Gibson, A., et al. (2019). Distinct inflammatory and wound healing responses to complex caudal fin injuries of larval zebrafish. Elife 8:e45976. doi: 10.7554/eLife.45976

Monterroso, P., Alves, P. C., and Ferreras, P. (2014). Promiscuous colonies queens generate honeybee with a critical of waggle-dancing foragers minority. Behav. Ecol. Sociobiol. 64, 875-889. doi: 10.1007/S00265-0

Morales, R. A., and Allende, M. L. (2019). Peripheral macrophages promote tissue regeneration in zebrafish by fine-tuning the inflammatory response. Front. Immunol. 10:253. doi: 10.3389/fimmu.2019.00253

Murawala, H., Ranadive, I., Patel, S., and Balakrishnan, S. (2017). Temporal expression pattern of peptides in the regenerating caudal fin of teleost fish Poecilia latipinna with special emphasis on krt15 and myl-1. Eur. J. Exp. Biol. 7:21. doi: $10.21767 / 2248-9215.100021$

Nguyen-Chi, M., Laplace-Builhé, B., Travnickova, J., Luz-Crawford, P., Tejedor, G., Lutfalla, G., et al. (2017). TNF signaling and macrophages govern fin regeneration in zebrafish larvae. Cell Death Dis. 8:e2979. doi: 10.1038/cddis. 2017.374
Nogueira, A. F., Nogueira, A. F., Costa, C. M., Lorena, J., Moreira, R. N., FrotaLima, G. N., et al. (2016). Tetrapod limb and sarcopterygian fin regeneration share a core genetic programme. Nat. Commun. 7:13364. doi: 10.1038/ ncomms 13364

Offen, N., Blum, N., Meyer, A., and Begemann, G. (2008). Fgfr1 signalling in the development of a sexually selected trait in vertebrates, the sword of swordtail fish. BMC Dev. Biol. 8:98. doi: 10.1186/1471-213X-8-98

Olendorf, R., Rodd, F. H., Punzalan, D., Houde, A. E., Hurt, C., and Reznick, D. N. (2006). Frequency-dependent survival in natural guppy populations. Nature 441, 633-636. doi: 10.1038/nature04646

O'Steen, S., Cullum, A. J., and Bennett, A. F. (2002). Rapid evolution of escape ability in trinidadian guppies (Poecilia reticulata). Evolution 56, 776-784. doi: 10.1111/j.0014-3820.2002.tb01388.x

Pafilis, P., Foufopoulos, J., Poulakakis, N., Lymberakis, P., and Valakos, E. D. (2009). Tail shedding in island lizards [lacertidae, reptilia]: decline of antipredator defenses in relaxed predation environments. Evolution 63, 12621278. doi: $10.1111 / j .1558-5646.2009 .00635 . x$

Panhuis, T. M., Butlin, R., Zuk, M., and Tregenza, T. (2001). Sexual selection and speciation. Trends Ecol. Evol. 16, 364-371.

Pápai, N., Kagan, F., Csikós, G., Kosztelnik, M., Vellai, T., and Varga, M. (2019). No correlation between endo-and exoskeletal regenerative capacities in teleost species. Fishes 4:51. doi: 10.3390/fishes4040051

Paredes, L. C., Camara, N. O. S., and Braga, T. T. (2019). Understanding the metabolic profile of macrophages during the regenerative process in zebrafish. Front. Physiol. 10:617. doi: 10.3389/fphys.2019.00617

Patel, S., Ranadive, I., Desai, I., and Balakrishnan, S. (2019). Regeneration of caudal fin in Poecilia latipinna: insights into the progressive tissue morphogenesis. Organogenesis 15, 35-42. doi: 10.1080/15476278.2019.1633168

Petrie, T. A., Strand, N. S., Tsung-Yang, C., Rabinowitz, J. S., and Moon, R. T. (2014). Macrophages modulate adult zebrafish tail fin regeneration. Development 141, 2581-2591. doi: 10.1242/dev.098459

Pfefferli, C., and Jaźwiñska, A. (2015). The art of fin regeneration in zebrafish. Regeneration 2, 72-83. doi: 10.1002/reg2.33

Phipps, L. S., Marshall, L., Dorey, K., and Amaya, E. (2020). Model systems for regeneration: Xenopus. Development 147:dev180844. doi: 10.1242/dev.180844

Pilastro, A., Giacomello, E., and Bisazza, A. (1997). Sexual selection for small size in male mosquito fisb (Gambusia holbrooki). Proc. Biol. Sci. 264, 1125-1129. doi: 10.1098/rspb.1997.0155

Plaut, I. (2000). Effects of fin size on swimming performance, swimming behaviour and routine activity of zebrafish Danio rerio. J. Exp. Biol. 203, $813-820$.

Plaut, I. (2002). Does pregnancy affect swimming performance of female Mosquitofish, Gambusia affinis? Funct. Ecol. 16, 290-295. doi: 10.1046/j.13652435.2002.00638.x

Pollux, B. J. A., Meredith, R. W., Springer, M. S., Garland, T., and Reznick, D. N. (2014). The evolution of the placenta drives a shift in sexual selection in livebearing fish. Nature 513, 233-236. doi: 10.1038/nature13451

Pollux, B. J. A., Pires, M. N., Banet, A. I., and Reznick, D. N. (2009). The evolution of placentas in the fish family Poeciliidae - an empirical study of macroevolution. Annu. Rev. Ecol. Evol. Syst. 40, 271-289.

Pollux, B. J. A., and Reznick, D. N. (2011). Matrotrophy limits a female's ability to adaptively adjust offspring size and fecundity in fluctuating environments. Funct. Ecol. 25, 747-756.

Porrello, E. R., Mahmoud, A. I., Simpson, E., Hill, J. A., Richardson, J. A., Olson, E. N., et al. (2011). Transient regenerative potential of the neonatal mouse heart. Science 331, 1078-1080. doi: 10.1126/science. 1200708

Prenter, J., Taylor, P. W., and Elwood, R. W. (2008). Large body size for winning and large swords for winning quickly in swordtail males, Xiphophorus helleri. Anim. Behav. 75, 1981-1987. doi: 10.1016/j.anbehav.2007. 12.008

Price, S. A., Friedman, S. T., and Wainwright, P. C. (2015). How predation shaped fish: the impact of fin spines on body form evolution across teleosts. Proc. Biol. Sci. 282:20151428. doi: 10.1098/rspb.2015.1428

Ptacek, M. B. (2005). "Mating signal divergence, sexueal selection, and species recognition in Mollies (Poeciliidae: Poecilia: Mollienesia)," in Viviparous Fishes, eds M. C. Uribe and H. J. Grier (Homestead, FL: New Life Publications), $72-87$. 
Ptacek, M. B., and Travis, J. (1996). Inter-population variation in male mating behaviours in the sailfin mollie, Poecilia latipinna. Anim. Behav. 52, 59-71. doi: 10.1006/anbe.1996.0152

Quicazan-Rubio, E. M., Van Leeuwen, J. L., Van Manen, K., Fleuren, M., Pollux, B. J., and Stamhuis, E. J. (2019). Coasting in live-bearing fish: the drag penalty of being pregnant. J. R. Soc. Interface 16:20180714. doi: 10.1098/rsif.2018.0714

Ramsey, M. E., Wong, R. Y., and Cummings, M. E. (2011). Estradiol, reproductive cycle and preference behavior in a northern swordtail. Gen. Comp. Endocrinol. 170, 381-390. doi: 10.1016/j.ygcen.2010.10.012

Reznick, D. (1983). The structure of guppy life histories: the tradeoff between growth and reproduction. Ecology 64, 862-873. doi: 10.2307/1937209

Reznick, D., Callahan, H., and Llauredo, R. (1996). Maternal effects on offspring quality in Poeciliid. Am. Zool. 36, 147-156.

Reznick, D., and Endler, J. A. (1982). The impact of predation on life history evolution in Trinidadian guppies. Evolution 36:1236. doi: 10.2307/2408156

Reznick, D. A., Bryga, H., and Endler, J. (1990). Experimentally induced life-history evolution in a natural population. Nature 346, 357-359. doi: $10.1111 / \mathrm{j} .1558$ 5646.2010.01188.x

Reznick, D. N. (1982). The impact of predation on life history evolution in Trinidadian guppies: the genetic components of observed life history differences. Evolution 36, 1236-1250. doi: 10.2307/2407978

Reznick, D. N., Bryant, M. J., Roff, D., Ghalambor, C. K., and Ghalambor, D. E. (2004). Effect of extrinsic mortality on the evolution of senescence in guppies. Nature 431, 1095-1099. doi: 10.1038/nature02936

Reznick, D. N., and Bryga, H. A. (1996). Life-history evolution in guppies (Poecilia reticulata?: Poeciliidae). V . Genetic basis of parallelism in life histories. Am Nat. 147, 339-359.

Reznick, D. N., Mateos, M., and Springer, M. S. (2002). Independent origins and rapid evolution of the placenta in the fish genus Poeciliopsis. Science 298, 1018-1020. doi: 10.1126/science. 1076018

Reznick, D. N., Shaw, F. H., Rodd, F. H., and Shaw, R. G. (1997). Evaluation of the rate of evolution in natural populations of guppies (Poecilia reticulata). Science 275, 1934-1937. doi: 10.1126/science.275.5308.1934

Rosenthal, G. G., and Evans, C. S. (1998). Female preference for swords in Xiphophorus helleri reflects a bias for large apparent size. Proc. Natl. Acad. Sci. U. S. A. 95, 4431-4436. doi: 10.1073/pnas.95.8.4431

Ryan, M. J., and Causey, B. A. (1989). "Alternative" mating behavior in the swordtails Xiphophorus nigrensis and Xiphophorus pygmaeus (Pisces: Poeciliidae). Behav. Ecol. Sociobiol. 24, 341-348.

Ryan, M. J., Pease, C. M., and Morris, M. R. (1992). A genetic polymorphism in the swordtail Xiphophorus nigrensis?: testing the prediction of equal fitnesses. Am. Nat. 139, 21-31.

Sanz-Morejón, A., García-Redondo, A. B., Reuter, H., Marques, I. J., Bates, T., Galardi-Castilla, M., et al. (2019). Wilms tumor 1b expression defines a proregenerative macrophage subtype and is required for organ regeneration in the zebrafish. Cell Rep. 28, 1296-1306.e6. doi: 10.1016/j.celrep.2019.06.091

Schartl, M., Walter, R. B., Shen, Y., Garcia, T., Catchen, J., Amores, A., et al. (2013). The genome of the platyfish, Xiphophorus maculatus, provides insights into evolutionary adaptation and several complex traits. Nat. Genet. 45, 567-572. doi: 10.1038/ng.2604

Sehring, I. M., and Weidinger, G. (2020). Recent advancements in understanding fin regeneration in zebrafish. Wiley Interdiscip. Rev. Dev. Biol. 9:e367. doi: 10.1002/wdev.367

Seifert, A. W., Monaghan, J. R., Smith, M. D., Pasch, B., Stier, A. C., Michonneau, F., et al. (2012). The influence of fundamental traits on mechanisms controlling appendage regeneration. Biol. Rev. 87, 330-345. doi: 10.1111/j.1469-185X.2011. 00199.x

Sharma, A., and Rudra, D. (2018). Emerging functions of regulatory T cells in tissue homeostasis. Front. Immunol. 9:883. doi: 10.3389/fimmu.2018.00883

Shen, Y., Chalopin, D., Garcia, T., Boswell, M., Boswell, W., Shiryev, S. A., et al. (2016). X. couchianus and X. hellerii genome models provide genomic variation insight among Xiphophorus species. BMC Genomics 17:37. doi: 10 . 1186/s12864-015-2361-z

Shibata, E., Liu, Z., Kawasaki, T., Sakai, N., and Kawakami, A. (2018). Robust and local positional information within a fin ray directs fin length during zebrafish regeneration. Dev. Growth Differ. 60, 354-364. doi: 10.1111/dgd.12558

Sinclair, E. L., Ward, A. J., and Seebacher, F. (2011). Aggression-induced fin damage modulates trade-offs in burst and endurance swimming performance of mosquitofish. J. Zool. 283, 243-248. doi: 10.1111/j.1469-7998.2010.00 776.x

Stewart, S., Gomez, A. W., Armstrong, B. E., Henner, A., and Stankunas, K. (2014). Sequential and opposing activities of Wnt and BMP coordinate zebrafish bone regeneration. Cell Rep. 6, 482-498. doi: 10.1016/j.celrep.2014. 01.010

Stewart, S., Yette, G. A., Le Bleu, H. K., Henner, A. L., Braunstein, J. A., Chehab, J. W., et al. (2019). Skeletal geometry and niche transitions restore organ size and shape during zebrafish fin regeneration. bioRxiv [Preprint]. doi: 10.1101/ 606970

Sugimoto, K., Hui, S. P., Sheng, D. Z., Nakayama, M., and Kikuchi, K. (2017). Zebrafish FOXP3 is required for the maintenance of immune tolerance. Dev. Comp. Immunol. 73, 156-162. doi: 10.1016/j.dci.2017.03.023

Taranger, G. L., Carrillo, M., Schulz, R. W., Fontaine, P., Zanuy, S., Felip, A., et al. (2010). Control of puberty in farmed fish. Gen. Comp. Endocrinol. 165, 483-515. doi: 10.1016/j.ygcen.2009.05.004

Thomaz, A. T., Carvalho, T. P., Malabarba, L. R., and Knowles, L. L. (2019). Geographic distributions, phenotypes, and phylogenetic relationships of Phalloceros (Cyprinodontiformes: Poeciliidae): insights about diversification among sympatric species pools. Mol. Phylogenet. Evol. 132, 265-274. doi: 10. 1016/j.ympev.2018.12.008

Tiozzo, S., and Copley, R. R. (2015). Reconsidering regeneration in metazoans: an evo-devo approach. Front. Ecol. Evol. 3:67. doi: 10.3389/fevo.2015.00067

Tobler, M., Kelley, J. L., Plath, M., and Riesch, R. (2018). Extreme environments and the origins of biodiversity: adaptation and speciation in sulphide spring fishes. Mol. Ecol. 27, 843-859. doi: 10.1111/mec.14497

Travis, J., and Woodward, B. D. (1989). Social context and courtship flexibility in male sailfin mollies, Poecilia latipinna (Pisces: Poecillidae). Anim. Behav. 38, 1001-1011. doi: 10.1016/S0003-3472(89)80139-3

Trexler, J. (1997). Resource availability and plasticity in offspring provisioning: embryo nourishment in sailfin mollies. Ecology 78, 1370-1381.

Van Kruistum, H., Guernsey, M. W., Baker, J. C., Kloet, S. L., Groenen, M. A., Pollux, B. J., et al. (2020). The genomes of the livebearing fish species Poeciliopsis retropinna and Poeciliopsis turrubarensis reflect their different reproductive strategies. Mol. Biol. Evol. 37, 1376-1386. doi: 10.1093/molbev/msaa011

Van Kruistum, H., Van Den Heuvel, J., Travis, J., Kraaijeveld, K., Zwaan, B. J., Groenen, M. A., et al. (2019). The genome of the live-bearing fish Heterandria formosa implicates a role of conserved vertebrate genes in the evolution of placental fish. BMC Evol. Biol. 19:156. doi: 10.1186/s12862-0191484-2

Vogg, M. C., Galliot, B., and Tsiairis, C. D. (2019). Model systems for regeneration: Hydra. Development 146:dev177212. doi: 10.1242/dev.177212

Wagner, G. P., and Misof, B. Y. (1992). Evolutionary modification of regenerative capability in vertebrates: a comparative study on teleost pectoral fin regeneration. J. Exp. Zool. 261, 62-78. doi: 10.1002/jez.1402610108

Wang, Y. T., Tseng, T. L., Kuo, Y. C., Yu, J. K., Su, Y. H., Poss, K. D., et al. (2019). Genetic reprogramming of positional memory in a regenerating appendage. Curr. Biol. 29, 4193-4207. doi: 10.1016/j.cub.2019.10.038

Warren, W. C., García-Pérez, R., Xu, S., Lampert, K. P., Chalopin, D., Stöck, M., et al. (2018). Clonal polymorphism and high heterozygosity in the celibate genome of the Amazon molly. Nat. Ecol. Evol. 2, 669-679. doi: 10.1038/s41559018-0473-y

Webb, P. W. (1973). Effects of partial caudal-fin amputation on the kinematics and metabolic rate of underyearling sockeye salmon (Oncorhynchus nerka) at steady swimming speeds. J. Exp. Biol. 59, 565-582.

Webb, P. W. (1977). Effects of median-fin amputation on fast-start performance of rainbow trout (Salmo gairdneri). J. Exp. Biol. 68, 123-135.

Weber, M. J., Rounds, K. D., and Brown, M. L. (2012). Phenotypic variation and associated predation risk of juvenile common carp Cyprinus carpio. J. Fish Biol. 80, 49-60. doi: 10.1111/j.1095-8649.2011.03140.x

Wehner, D., Cizelsky, W., Vasudevaro, M. D., Özhan, G., Haase, C., KagermeierSchenk, B., et al. (2014). Wnt/ $\beta$-catenin signaling defines organizing centers that orchestrate growth and differentiation of the regenerating zebrafish caudal fin. Cell Rep. 6, 467-481. doi: 10.1016/j.celrep.2013.12.036

Wehner, D., and Weidinger, G. (2015). Signaling networks organizing regenerative growth of the zebrafish fin. Trends Genet. 31, 336-343. doi: 10.1016/j.tig.2015. 03.012 
Winemiller, K. O. (1990). Caudal eyespots as deterrents against fin predation in the neoptropical cichlid Astronotus ocellatus. Copeia 3, 665-673.

Zauner, H., Begemann, G., Marí-Beffa, M., and Meyer, A. (2003). Differential regulation of msx genes in the development of the gonopodium, an intromittent organ, and of the "sword," a sexually selected trait of swordtail fishes (Xiphophorus). Evol. Dev. 5, 466-477. doi: 10.1046/j.1525-142X.2003.03053.x

Ziskowski, J., Mercado-Allen, R., Pereira, J. J., and Goldberg, R. (2008). The effects of fin rot disease and sampling method on blood chemistry and hematocrit measurements of winter flounder, Pseudopleuronectes americanus from New Haven Harbor (1987-1990). Mar. Pollut. Bull. 56, 740-750. doi: 10.1016/j. marpolbul.2007.12.007

Zwi, S. F., Choron, C., Zheng, D., Nguyen, D., Zhang, Y., Roshal, C., et al. (2019). Pharmacological enhancement of regeneration-dependent regulatory t cell recruitment in zebrafish. Int. J. Mol. Sci. 20:5189. doi: 10.3390/ijms2020 5189

Conflict of Interest: The authors declare that the research was conducted in the absence of any commercial or financial relationships that could be construed as a potential conflict of interest.

Copyright $\odot 2021$ Safian, Wiegertjes and Pollux. This is an open-access article distributed under the terms of the Creative Commons Attribution License (CC BY). The use, distribution or reproduction in other forums is permitted, provided the original author(s) and the copyright owner(s) are credited and that the original publication in this journal is cited, in accordance with accepted academic practice. No use, distribution or reproduction is permitted which does not comply with these terms. 